For registration of existing types in this studbook it requires something more than speed records; there must be evidence of individual Arab characteristics to be worthy of breeding to the pure Arab.

By careful selection we will build up a selected Americo-Arab type. The United States Department of Agriculture has taken the initiative in this matter in selecting for restoring the Morgan type and in creating an American Coach horse.

By a proper coöperation and system of circuit breeding of selected units from our best native stock, we can establish a higher respect for the American-bred horse and become a nation of exporters of high-class horses instead of a nation of importers. We will have the best that soil, climate, science, and care can produce.

\title{
BREEDING OSTRICHES FOR PLUMES
}

\author{
Charleg F. Holden \\ South Pasadena, Cal.
}

Twenty odd years ago Mr. Edwin Cawston conceived the idea of raising ostriches in southern California on a commercial scale. $\mathrm{He}$ went to Africa, collected some fifty good birds and arranged to have them shipped to this country. Many difficulties had to be overcomc, not the least of which was the opposition manifested on the part of the South African Government. However, a few of the birds were finally landed safely in southern California.

Since that time immense improvements have been made in ostrich feather growing by applying American methods. The ostrich feathers of Africa are produced at times under very poor or adverse conditions, whereas the American ostrich feathers are the product of careful breeding, feeding, and care in the congenial climate near Ios Angeles. The result is that the feathers are much finer, glossier, and stronger.

This ostrich farm is one of the most delightful spots in southern California. Originally it was one of those oak-clad arroyo banks found at intervals. All these splendid trees were preserved and made part of the general effect, many rare plants and shrubs being introduced. With judicious terracing, cobblestone ditches, and paths, fine landscape effects have been secured. In few places can one see such fine examples of Asparagus Plumosus, many of the fronds extending up onto the roofs of the buildings and high up into the oak trees. There are also splendid examples of ivy-draped oak trees. 
The ordinary ostrich egg weighs about three and one-quarter pounds. The eggs are laid one every other day until twelve or thirteen have accumulated. Sometimes the mother bird refuses to sit, in which case the eggs are put into an incubator for the reason that the male bird, which usually covers them during the night, will not do so unless the mother covers them during the day.

In about forty days the eggs begin to hatch, and the chicks come out full fledged and quite strong, standing about twelve inches high. They are covered with short stubby feathers reminding one of a bunch of dark colored excelsior. For the first two or three days they eat nothing but bits of gravel and shell. Then they begin on the tender shoots of alfalfa and other green food.

The ostrich chicks grow very rapidly, increasing in size about a foot a month. During this period they require a great deal of attention

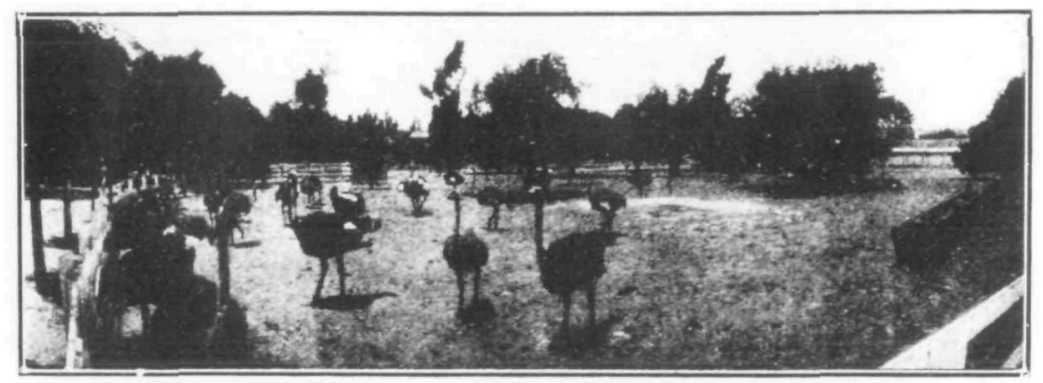

Fro. 1.-Paddoct on an Oethich-Breedima Faru im Calmonmia.

as they receive no care whatever from the mother birds. During the incubation, however, the mothers are very faithful, covering the eggs during the hardest storms, even if the nest, which is mercly a hole scooped in the ground, becomes filled with water. Young ostriches do not show any distinction of sex until they are fourteen months old, when the male takes on the black feathers.

There are two recognized varieties of African ostrich; the Nubian, which is the larger of the two, sometimes reaches a height of nine and one-half feet. The tallest ostrich in the Cawston flock stands eight feet high. When tempted with an orange or other dainty it can reach to a height of fully ten feet. The average height of these birds is seven feet. The eggs of the Nubian bird are larger and quite smooth and weigh between three and four pounds each. The period of incubittion is forty diays. The feathers of the Nubian are more curly but niarrower than those of the South African ostrich. Crossed with 
the South African they produce a finer grade of feathers than do either of the parent stocks.

The birds are plucked about every eight or nine months. They are not really "plucked" at all, but the wing plumes and the tail feathers are carefully clipped, one at a time. the stump of the quill being allowed to remain until it drops out of its own accord.

Feathers are graded to an exact scale. First they sre sorted as to color. Then each given quality is assorted as to length, varying from the short ones up to plumes twenty-four inches long. Then each length is sorted as to width, there being six widths. This means that there are more than five hundred distinct grades of feathers. It must

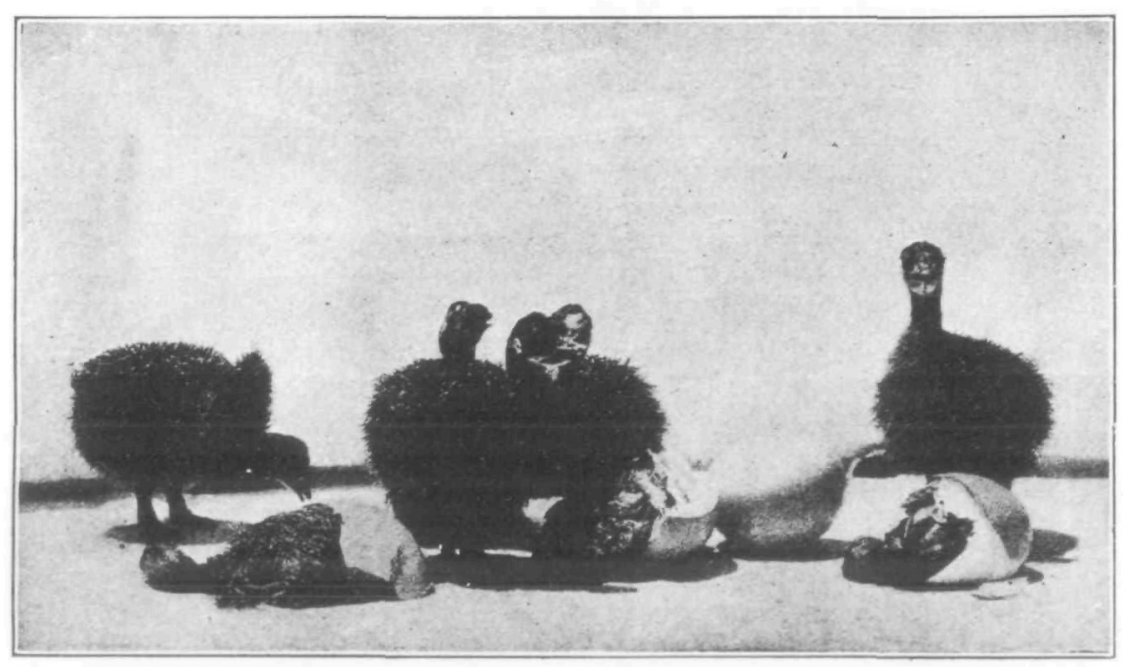

Fig. 2.-CaLtornu Otractes.

not be understood that this refers to colors at all. These five hundred different grades are each of them dyed into almost innumerable colors and shades, and one can therefore see that the total stock comprises thousands of varieties. The sizes of the fancy first grade feathers are about twenty-one inches in length and about fifteen inches in width. This size is worth on the market about $\$ 400$ per pound; it takes eighty feathers of this size to weigh one pound, approximately. On the tip of each wing of the male bird there is one single feather called the bycock. It is a natural mottle of white and brown, and very beautiful. The black and the white feathers of the male birds are of equal commercial value. The feathers of the female bird have a value of 
about 20 per cent less than those of the male. The average value of a plucking per annum is about \$25; exceptionally good birds are worth as high as 45. Each wing has twenty-six plumes. There are about sixty tail-feathers. The feathers on the body of the bird have very small value and are used in making boas and other cheaper grade feather articles.

When feathers come to be manufactured after being dyed, the first process is another careful sorting for quality. It is as if a harrel of apples were graded, first for size and then were examined one by one to see that each conformed in every minute particular to the standard. Thus are brought together in each plume or boa or other article feathers not only of the same size and general quality but of such a texture that each will curl in just the same way.

Although the ostriches require a great deal of attention when small, once they are grown they are very hardy. So far the only disease known among the ostriches is what is called the Douglas worm, a minute parasite which clings to the walls of the stomach. This is not of a serious nature.

The neck of an ostrich is a wonderful part of its anatomy. The average length of the neck is a little less than three feet, but in the flock at the Cawston home farm, there is one big Nubian female with a neck measuring three and one-half feet. An adult ostrich when in full swing covers about twenty-two feet at a stride and can easily outdistance an ordinary horse. Their gait, both in running and walking, has a peculiar swinging roll which at first seems awkward, but there is a rhythm about it that is really very graceful.

The bill of an ostrich opens fully four inches, and an adult one makes no trouble over swallowing an orange whole-a big navel orange, with a diameter of three and one-half inches. Moreover, some ostriches will catch these oranges as fast as they are tossed, swallowing one after another until ten or twelve huge globes can be counted rolling down the long neck at the same time. The California ostriches are almost equally fond of sugar beets and quickly snap up rectangular chunks measuring from three to four inches, disposing of them much the same as they do of the oranges. The old saw about "a stomach like an ostrich's" is not altogether beside the mark, for the ostrich will eat literally anything, including nails and glass. They demand large quantities of gravel or other gritty substance. The omnivorous appetite of the ostrich often gives rise to amusing incidents at the Cawston farm. Perhaps the queerest stunt of all was when one old patriarch shot his head over the railing 
and seized a long green veil fluttering from a lady's hat. Nor did he stop until he had drawn the veil off and swallowed it entire! An ostrich eats nearly one-fourth as much as a cow. They are extremely fond of green alfalfa and eat several pounds a day. They are also given large quantities of such vegetables as carrots, beets, turnips, etc. Their diet must be carefully arranged if they are to produce the silkiest and glossiest feathers. Rational methods of feeding and handling have increased the feather production of the birds very considerably.

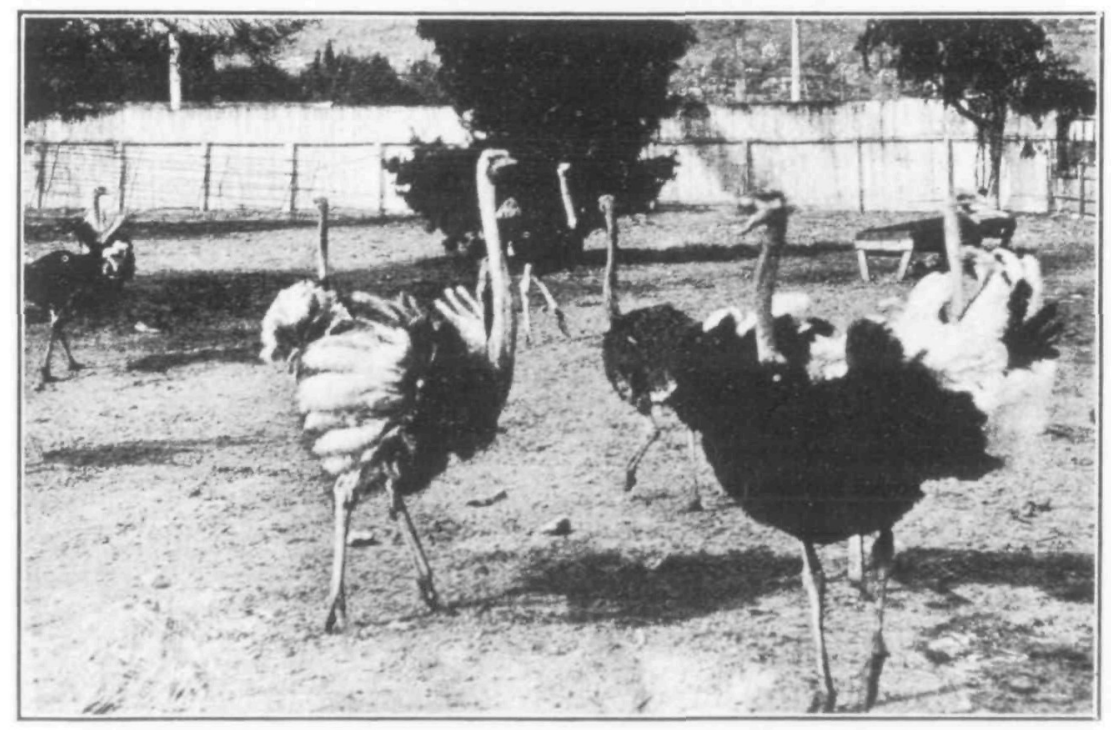

Fia. 3-Male and Female Ootruch.

Of all animals, the ostrich has the smallest head in proportion to its body weight. The eye is about in proportion to the size of the bird and therefore appears out of proportion to the rest of the head. The ostrich's eye is about the size of a good-sized marble. However, he can see the most minute object. They are particularly attracted by anything that sparkles or glitters, and it is dangerous to be near them with any article of adornment. The eyelid of the ostrich does not move over the eye, but instead there is a separate film which flashes across it from time to time, reminding one of the shutter of a camera.

Attendants declare that these birds have no brains. They say that the man who has fed them and cared for them for years takes just as much risk in going into the pens as the utmost stranger. They 
seem to manifest no feelings of affection or of friendship, such as most other birds or animals do. They are extremely treacherous-or a better word is "finicky"; a trivial circumstance will enrage them. They start a fight against other birds or against the keepers without any discernible provocation.

When an ostrich issues a formal challenge to fight, he sits down, spreads out his wings, draws his head back against his body, and then repeatedly flaps his wings while waving his head from sicle to side and bringing it against his body with a resounding thump. This is evidently more of an attempt to frighten off the enemy than a preliminary to fighting, for if one of them really wants to do damage he does not wait for any such preliminaries but issues a screaming hiss, throws up his wings, and pounces upon his opponent. The fighting is all done with the feet, for the bill of an ostrich is comparatively soft. The foot of the ostrich consists of one long toe, sticking out directly in front, which ends in a heavy thick claw, and a slightly shorter toe on the outside, standing at an angle. He fights by kicking-it would be more accurately described by the word "striking"for he raises his foot as high as possible and then brings it down with a blow that would fell a cow. When ostriches are kept in flocks many individuals may be noticed whose breasts are torn and scarred from the savage down-cut of that cruel spur. Most commonly their fights are over family affairs. Ostriches mate for life and once mated the male will tolerate no interference from the unmated birds. This recalls that about four years ago one of the finest birds at the home farm killed his mate in the night by kicking her to death, and the attendants aver that it was because he was jealous of an unmated bird in the adjoining enclosure. He was afterwards turned back with the unmated birds and selected a now mate with which he has lived peacefully for four years.

The best producers at the farm are George and Martha Washington. These birds are twenty-four years old. They secm to have profited by their experience, for they hatch more chicks at at sctting and do it with less fuss than any other pair. The attendiunts claim that they leave their nests longer and spend much less time and trouble than other pairs; still at each setting last year they brought off eleven fine chicks, whereas it is not unusual for a pair to secure only three or four or five chicks. If this pair hawe actually beren as sueressful in past years as last, they would now have to their credit four humlred and forty ostriches. The life of an est rich is between 25) and 355 years: 